\title{
Exposure Standards for Digital and Analogue Dry Skull Orthopantomography
}

Thiago L. Beaini*, Paulo Eduardo Miamoto Dias, Rodolfo F. H. Melani

Master degree on Legal dentistry at the dental school of the University of São Paulo, Brazil

\begin{abstract}
Forensic or scientific practices may require producing orthopantomography of dry skulls, that lack soft tissue, therefore modifications on the usual technique should be necessary. With the objective of standardizing the postmortem digital and analogue panoramic radiography this research produced a single a digital radiography and 13 analogue panoramic images, using different exposure configurations and four different objects to try to overcome the effects of the lack of soft tissue radiation absorption on the analog radiographs. A gel based ice pack, a $20 \mathrm{~mm}$ dental wax block, and a $0.5 \mathrm{~mm}$ metallic foil were placed in different points of the device. Also a previously exposed and developed film was placed inside the cassette between the unexposed film and the intensifying screen. The images were presented to 15 dentists of several specialties, who graded and ranked the images. In conclusion, the digital panoramic was easily obtained at a $60 \mathrm{kV}$ and $2 \mathrm{~mA}$ settings and on analog equipments the use of two films inside the cassette achieved best results with $63 \mathrm{kV}$ and $06 \mathrm{~mA}$ exposure settings.
\end{abstract}

Keywords: Dental identification; Forensic odontology; Oral radiology; Forensic radiology

\section{Introduction}

Dry skull's Orthopantomography (OPG) are frequently used on scientific research or forensic investigations. It is stated that the use of the dental methods is a reliable tool when other identification methods fail [1-10]. The human dentition and its features can give the forensic team a large number of singularities that can prove, by direct comparison, that a body under examination is indeed a supposed individual once examined [11,4]. This is the baseline for dental identification. In these situations, the antemortem (AM) radiologic data presented will determine the radiological exams to be conducted. Since the quality of the AM radiographs presented cannot be controlled $[12,13,4]$ one must try to produce similar images with the best quality as possible.

As a result of better hygiene habits, water fluoridation, advances on Dentistry preventive practices and greater access of the population to it, a decrease on the number of restorations can be noted, especially among the younger individuals [10]. This new reality has a major impact on dental identification as the number of AM data available can be supposedly reduced due to less dental treatments executed $[10,14]$. However the same facilitated access to dental care that can decrease number of caries, can also offer another important aid to dental identification as other non restorative treatments, such as orthodontics, became usual. This specialty requires a series of complementary exams to almost every patient, such as pictures, models, panoramic radiographs, lateral and postero-anterior cephalometric analysis [15$16]$.

The panoramic radiograph is one of the complementary exams most required by dentists for diagnostic purposes. Along with periapical images, for years it has been playing an important role in dentistry [17]. Despite the fact that it shows less details, especially at the of anterior teeth regions and surrounding, its popularity is due to the wide visualization of dental arches, maxillary and mandibulary bones provided by this exam [18]

To reproduce such image from a dry skull, for forensic comparison or academic research purposes, one will find two major challenges. First, is to correctly keep the skull in position, and second, is to compensate the impaired image quality caused by the lack of soft tissues. The skin, muscles and other structures absorb radiation, and the absence of these elements in skeletonized human remains may lead to the conclusion that less radiation, compared to the living exposure standards, should be enough for the correct exposure of the film. However, most of the extra oral radiologic equipments do not offer exposure settings compatible with this unique situation, often originating overexposed radiographs. It can be easily compensated when using digital OPG equipment, which allows the manipulation of the image for quality enhancements. However this kind of equipment is not found often in forensic laboratories [19] or many academic facilities. When working on an analogue equipment, a barrier may be placed between the film and the $\mathrm{X}$ ray outlet point to simulate the soft tissue absorbance in order to prevent the over exposition.

There are different methods and materials used to facilitate dry skull's radiography in the literature $[2,19]$, however no articles were found, comparing which material should be used to achieve best panoramic image quality.

The objectives of this research are to compare possible methodologies and determine which one produces the best quality panoramic images. To avoid personal preferences, the evaluation was carried ot by a group of 15 dentists of different specialties, who were calibrated and asked to grade the images according to the radiological technique standards and their professional experience to decide which radiograph achieved

${ }^{*}$ Corresponding author: Thiago L. Beaini, Master degree on Legal dentistry at the dental school of the University of São Paulo, Av. Lineu Prestes, 2227. Cidade Universitária, Brazil (CEP 05508-000), R. Maestro João Gomes de Araújo, $106 \mathrm{SL}$ 61, São Paulo, Brazil (CEP- 02332-020), Tel: (55) 11 2972- 4180; E-mail: tbeaini@ gmail.com

Received February 02, 2011; Accepted February 23, 2011; Published February 25, 2011

Citation: Beaini TL, Miamoto Dias PE, Melani RFH (2011) Exposure Standards for Digital and Analogue Dry Skull Orthopantomography. J Forensic Res 2:115. doi:10.4172/2157-7145.1000115

Copyright: @ 2011 Beaini TL, et al. This is an open-access article distributed unde the terms of the Creative Commons Attribution License, which permits unrestricted use, distribution, and reproduction in any medium, provided the original author and source are credited. 
a best quality. The results can guide future research involving dry skull's radiographs and forensic protocols when the analysis of panoramic radiographs are required for human identification.

\section{Materials and Methods}

A Human cranium in satisfactory state of preservation was selected from the Forensic Odontology laboratory of the University of São Paulo Dentistry school, and a single digital and 13 analogue radiographs were taken at an initial phase. The cranium had teeth in all sectors of both arcades but also a few teeth missing due to postmortem (PM) lost, a common phenomenon on Forensic Dentistry. As variations in skull anatomy can alter the image quality [20], a skull with maximum length of $190 \mathrm{~mm}$ (frontal-occipital), basion-bregma height of $14 \mathrm{~mm}$ and biparietal breadth of $14 \mathrm{~mm}$ was selected due to the good proportions between length and width measurements as found in the literature [2122]. It was then positioned in an acrylic device designed to keep it safely in the correct position during the procedure, without interfering in the image quality. All permissions were granted by the local ethics council under the 171/2009 protocol.

In living individuals, as the $\mathrm{X}$-ray reaches the spinal area, a significant increase of radiation dosage can be set so that the anterior teeth receive the correct amount of radiation. The OPGs used in this study were a digital Kodak ${ }^{\bullet} 8000 \mathrm{C}$ and a analogue Gnatus ${ }^{\oplus}, \mathrm{X}$ mind Pano Ceph. Both offered the possibility of turning this feature off, avoiding problems with overexposure faced by other authors $[2,19]$. The dental arch is located at a distance between 15 to $20 \mathrm{~cm}$ of the $\mathrm{X}$ ray release point, during the translation movement of the equipment.

An initial digital radiography was obtained on the digital Kodak ${ }^{\circ}$ $800 \mathrm{C}$ at the minimum exposure preset of $60 \mathrm{kV}$ and $2.0 \mathrm{~mA}$. It was automatically enhanced by the software provided by the manufacturer and easily achieved good visualization parameters described in the radiological literature [23], providing a quality goal for the analog radiographs evaluation as observed in Figure 1.

In the 13 film based radiographs, several exposures settings were tested in radiographs 1 to 6 but none resulted in good quality images. Afterwards, four different materials were placed in specific points of the equipment in order to compensate for the lack of soft tissue and allow the correct exposure of the film (Table 1).

Initially three materials were placed in front of the cassette's opening first and then at the X ray outlet position (Figure 2) to test if the position of the barrier could interfere with image quality. The dimensions (height and width) of the barriers were not relevant as long as it covered the intended area, but the thickness is critical since the material could collide with the skull during the equipment's translation trajectory around the head causing an accidental fall of the human

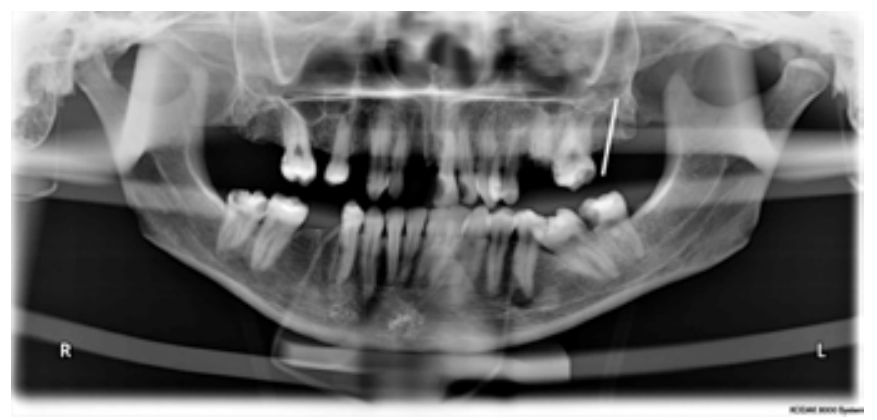

Figure 1: Digital OPG with characteristics compatible with quality standards.

\begin{tabular}{|c|c|c|c|c|}
\hline X ray Number & $\mathrm{kVa}$ & $\mathrm{mA}$ & Material & $\begin{array}{c}\text { Cervical } \\
\text { Compensation }\end{array}$ \\
\hline 1. & 71 & 10 & None & Activated \\
\hline 2. & 63 & 10 & none & Off \\
\hline 3. & 71 & 10 & none & Off \\
\hline 4. & 63 & 10 & none & Off \\
\hline 5. & 71 & 6 & none & Off \\
\hline 6. & 63 & 6 & none & Off \\
\hline 7. & 63 & 6 & Ice pack at the cassette opening & Off \\
\hline 8. & 63 & 6 & Ice pack at the $X$ ray outlet & Off \\
\hline 9. & 63 & 6 & Wax at the cassette opening & Off \\
\hline 10. & 63 & 6 & Wax at the X ray outlet & Off \\
\hline 11. & 63 & 6 & Metal foil at the cassette opening & Off \\
\hline 12. & 63 & 6 & Metal foil at the X ray outlet & Off \\
\hline 13. & 63 & 6 & Extra film inside the Cassette & \\
\hline
\end{tabular}

Table 1: Description of the exposure settings, use of barriers and its positions, and the use of cervical compensation.

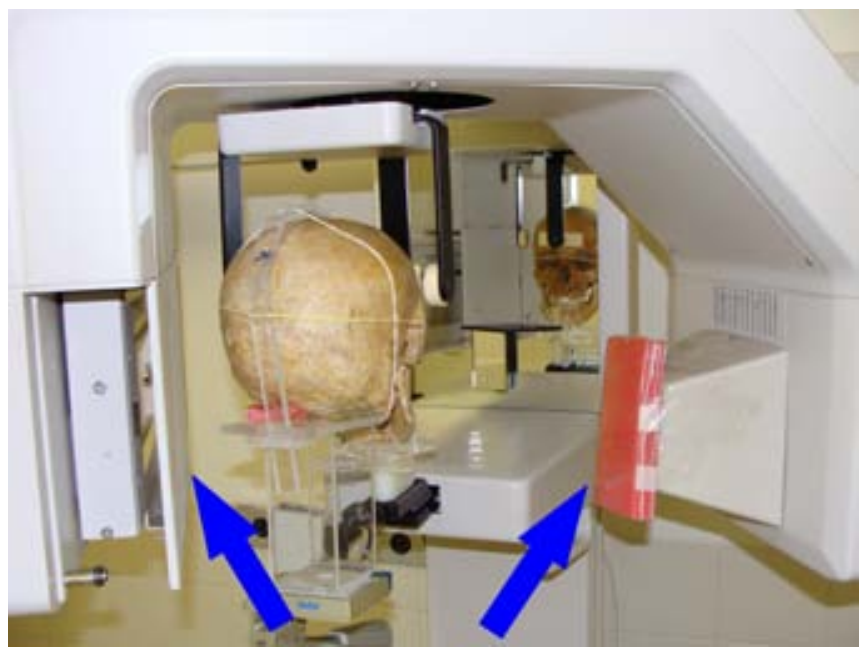

Figure 2: Positions of the first 3 external barriers, $\mathrm{X}$ ray outlet (right arrow) and cassette opening (left arrow).

remains. The cassette opening is narrow, but $150 \mathrm{~mm}$ high and the $\mathrm{X}$ ray outlet area can vary depending on the equipment but a square with sides measuring $150 \mathrm{~mm}$ should be enough to cover both completely.

The first barrier to be tested was a plastic ice pack, which is a cheap and easily available material. As a bag filled with gel, adhesive tape was applied around it to avoid deformation, as the gel concentrates at the bottom, therefore keeping the width uniform. The second barrier was made of 13 foils of dental wax shaped in a single $20 \mathrm{~mm}$ wide block. The third one was a metal plate, $0.5 \mathrm{~mm}$ thick. The metal used was a foil of zinc coated steel and it was, by far, the easier external material to keep in position, due to its light weight and plain shape (Figure 3 / Table 2).

At a final radiograph, a panoramic film, intentionally exposed to light was developed, resulting in a completely dark film. It was then placed between an unexposed film and the intensifying screen while the panoramic cassette was assembled in the dark room.

A $20 \mathrm{~mm}$ orthodontic wire was also attached to the skull, inside the empty upper second left molar socket. Its volumetric stability would be evaluated by measuring it in the resulting panoramics.

All the films were processed in an automatic processing machine $\left(\right.$ Revell $\left.{ }^{\circ}\right)$, in the same day, with new developing solutions, following the manufacturer's instruction for panoramic film development, at a 2.5 min speed preset. That should eliminate the chemical process as an interfering factor on the image quality. 
In the next phase of the research, 15 dentists, of different specialties and years of experience, analyzed the radiographs. This group of professionals had between 6 to 53 years of dental clinical practice on each specialty. Furthermore, some of them are faculty members used to both digital and analogue radiology on their daily practice. The radiologists and the stomatologist work at radiology institutes, analyzing hundreds of panoramics weekly (Table 3).

They were told that those were dry skull's panoramic images (to explain some missing anatomical structures) and then instructed to analyze the films in search of satisfying viewing of anatomic structures, good contrast and sharpness of the central and both right and left areas of the images. Afterwards, the standards of the literature [23] of an ideal image was explained and the digital image was also presented as an example. These professionals then graded the analog images (Table 2) according to the following scale:

0 - Non-visible anatomic structures.

1- Visible but not good enough quality for diagnostic purpose.

2- Visible and acceptable for diagnostic purpose.

3- Excellent for diagnostic purpose.

The grades were then loaded into a table and averaged by the number of examiners. Those averages were compared and the highest value was considered the best barrier. This method is well known to radiologists as the subjective method and frequently used in scientific research to avoid personal preferences [24-25].

\section{Results}

There was a considerable volume stability, noted when the orthodontic metal wire was measured in the films. However, in all images that it was visible enough to have its length established, it was measured to be $26 \mathrm{~mm}$ long, a 30 percent magnification, which is acceptable on orthopantomographies according to the literature $[23,18]$.

The film based radiographs 1 to 6 , several exposures settings were tested in radiographs, but none produced minimum quality images. The different settings of exposure did not improve the quality of the images, suggesting that the barriers at the outlet point along with

\begin{tabular}{|l|l|l|}
\hline \multicolumn{1}{|c|}{ Material } & \multicolumn{1}{c|}{ Caracteristic } & \multicolumn{1}{c|}{ Size / width } \\
\hline Ice pack & cellulose based gel & $140 \times 130 \mathrm{~m} /$ Average $30 \mathrm{~mm}$ \\
\hline Dental Wax & Solid wax block & $140 \times 140 \mathrm{~cm} / 20 \mathrm{~mm}$ \\
\hline Metal Foil & Solid metal & $130 \times 290 \mathrm{~cm} / 0,5 \mathrm{~mm}$ \\
\hline
\end{tabular}

Table 2: Description of the external materials used on $X$ rays $7-12$.

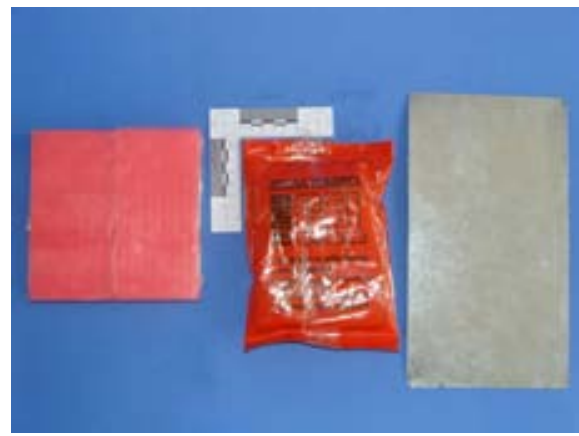

Figure 3: External material used: Dental wax (Left); Ice Pack (center); Metal foil (right).

\begin{tabular}{|l|c|c|c|}
\hline \multicolumn{1}{|c|}{ Specialty } & $\begin{array}{l}\text { Years of } \\
\text { experience }\end{array}$ & $\begin{array}{c}\text { Equipment most } \\
\text { used }\end{array}$ & $\begin{array}{c}\text { Estimated number of } \\
\text { radiographs analysed } \\
\text { weekly }\end{array}$ \\
\hline Orthodontists & $15-53$ & Analogue/ digital & $30-50$ \\
\hline Forensic dentistry & $10-27$ & Analogue/ digital & $2-50$ \\
\hline Radiologists & $10-15$ & Mostly Digital & Over 150 \\
\hline Stomatologist & 6 & Mostly Digital & Over 150 \\
\hline Maxillofacial surgeon & 15 & Analogue/ digital & Over 30 \\
\hline Dentistics & 9 & Analogue/ digital & 5 \\
\hline Endodontist & 23 & Analogue/ digital & 10 \\
\hline Prosthetics & 6 & Analogue/ digital & 10 \\
\hline
\end{tabular}

Table 3: Professional profiles of the evaluators

\begin{tabular}{|c|c|c|c|c|c|c|c|c|c|c|c|c|c|}
\hline $\begin{array}{c}\text { X Ray Number } \\
\text { Specialty }\end{array}$ & $\mathbf{1}$ & $\mathbf{2}$ & $\mathbf{3}$ & $\mathbf{4}$ & $\mathbf{5}$ & $\mathbf{6}$ & $\mathbf{7}$ & $\mathbf{8}$ & $\mathbf{9}$ & $\mathbf{1 0}$ & $\mathbf{1 1}$ & $\mathbf{1 2}$ & $\mathbf{1 3}$ \\
\hline Orthodontics 1 & 0 & 0 & 1 & 0 & 0 & 1 & 2 & 2 & 1 & 1 & 2 & 2 & 2 \\
\hline Orthodontics 2 & 0 & 0 & 0 & 0 & 0 & 1 & 2 & 2 & 1 & 1 & 2 & 2 & 2 \\
\hline Orthodontics 3 & 0 & 0 & 0 & 0 & 0 & 0 & 1 & 1 & 0 & 0 & 1 & 2 & 2 \\
\hline Orthodontics 4 & 0 & 0 & 1 & 0 & 0 & 1 & 3 & 3 & 1 & 2 & 2 & 2 & 3 \\
\hline Maxillofacial surgeon & 0 & 0 & 0 & 0 & 0 & 1 & 1 & 1 & 0 & 1 & 1 & 2 & 3 \\
\hline Stomatology & 0 & 0 & 0 & 0 & 0 & 0 & 1 & 3 & 1 & 1 & 2 & 2 & 3 \\
\hline Forensic 1 & 0 & 0 & 0 & 1 & 1 & 1 & 2 & 3 & 1 & 1 & 2 & 3 & 3 \\
\hline Forensic 2 & 0 & 0 & 1 & 0 & 1 & 2 & 3 & 3 & 2 & 3 & 3 & 3 & 3 \\
\hline Forensic 3 & 0 & 0 & 0 & 0 & 0 & 1 & 1 & 2 & 1 & 1 & 2 & 2 & 3 \\
\hline Forensic 4 & 0 & 0 & 0 & 0 & 0 & 1 & 2 & 2 & 1 & 1 & 1 & 1 & 2 \\
\hline Dentistics & 0 & 0 & 0 & 0 & 0 & 1 & 1 & 2 & 1 & 1 & 1 & 1 & 2 \\
\hline Radiology 1 & 0 & 0 & 0 & 0 & 0 & 0 & 1 & 1 & 0 & 0 & 1 & 2 & 3 \\
\hline Radiology 2 & 0 & 0 & 0 & 0 & 0 & 0 & 1 & 1 & 0 & 0 & 1 & 1 & 2 \\
\hline Endodontist & 0 & 0 & 0 & 0 & 0 & 1 & 1 & 2 & 1 & 1 & 2 & 3 & 3 \\
\hline Prosthetics & 0 & 0 & 0 & 0 & 0 & 0 & 1 & 1 & 0 & 1 & 1 & 2 & 2 \\
\hline Averages & 0 & 0 & 0,2 & 0,1 & 0,1 & 0,7 & 1,5 & 1,9 & 0,7 & 1 & 1,6 & 2 & 2,53 \\
\hline
\end{tabular}

Table 4: Scores given to each one of the panoramic images by dentists of different specialties.

minimum exposure settings are the best way to obtain quality on orthopantomographies.

The panoramic that was obtained with the two films technique, achieved the best values (Table 4). That provides the forensic crew a cheap, fast and reliable method for a sequence of radiographs when analogue equipment is the only one available.

To verify the statistical values of these results, The grades of each radiograph were compared with all others by a Variance analysis (ANOVA) and the Turkey Test. The $13^{\text {th }}$ radiograph did present the best simple average but according to the statistic analysis did not have significant differences with images 8 and 12 (Table 5).

\section{Discussion}

The personal standard for a good quality image can vary depending on the examiner's specialty and experience [26], since different aspects of the anatomical structure of the skull and teeth are more interesting for one or another group of professionals.

Considering separately the Digital and analogue radiography there are several differences concerning the technical difficulties presented by the analog exam that are easily compensated by program features that can be used to enhance image quality without altering it.

Most of the analogue images showed over exposition characteristics, especially at the anterior section of the dental arches. There was also a slight preference of the examiners to the images with the barriers placed at the $\mathrm{X}$-ray outlet ( $\mathrm{X}$ rays $8,10,12$ ) than the ones taken with the objects next to the cassette opening (X rays 7,9,11) when analyzing the results of the images using the same material as a barrier were compared. 
As reported, none of the films exposed without additional barriers at the analogue equipment was considered proper for diagnostic use. That shows that not even at the lowest preset of the OPG equipment, an image of good quality could be produced. When different materials were compared, the ice pack achieved a good quality average, almost at the score of 2 (visible and acceptable) for most of the examiners. The score drops when the images using the wax block as a barrier were analyzed and rises up to "acceptable" with the metal plate at the X-ray outlet. This dynamic of grades variation is observed in all evaluators results. However, with better view of the anterior teeth, the panoramic radiograph number 13 achieved the best average of 2.5 supporting other literature reports [19]. Although it did not have statistical difference with $\mathrm{X}$ ray 8 and 12 (two of the following top scores), it presented more significant differences than any other image. Furthermore the easy preparing of the equipment and reproducibility already gives this technique an advantage. These two non-significant differences are possibly due to a small number of examiners even though the number is larger than other researches in the literature [24-25].

When digitalized, film based radiographs does not achieve the quality standards of the original film [27], but the changes in density and contrast that leaded to the averages presented can still be noted in Figure 4 .

Besides the better image quality evaluated, the simple act of placing a developed film inside the cassette before inserting a new one, helps the chosen technique to be an even more convenient method. Accidental falls of the barriers attached to the equipment and other adaptations that could jeopardize the integrity of the human evidence are unwanted and may be avoided by this technique.

\begin{tabular}{|l|l|l|l|}
\hline & $\begin{array}{l}\text { Not Significant } \\
\text { difference } \\
\text { (X ray numbers) }\end{array}$ & $\mathbf{< 0 , 0 5}$ & $<\mathbf{0 , 0 1}$ \\
\hline$X$ ray 1 & $2,3,4,5$ & 6,9 & $7,8,10,11,12,13$ \\
\hline$X$ ray 2 & $1,3,4,5$ & 6,9 & $7,8,10,11,12,13$ \\
\hline$X$ ray 3 & $1,2,4,5,6,9$ & & $7,8,10,11,12,13$ \\
\hline$X$ ray 4 & $1,2,3,5$ & 6,9 & $7,8,10,11,12,13$ \\
\hline$X$ ray 5 & $1,2,3,4,6,9$ & & $7,8,10,11,12,13$ \\
\hline$X$ ray 6 & $3,5,9,10$ & $1,2,4$ & $7,8,11,12,13$ \\
\hline$X$ ray 7 & $8,10,11,12$ & & $1,2,3,4,5,6,9,13$ \\
\hline$X$ ray 8 & $7,11,12,13$ & $1,2,3,4,5,6,9,10$ \\
\hline$X$ ray 9 & $3,5,6,10$ & $1,2,4$ & $7,8,11,12,13$ \\
\hline$X$ ray 10 & $6,7,9,11$ & $1,2,3,4,5,8,11,12$ \\
\hline$X$ ray 11 & $7,8,10,12$ & $1,2,3,4,5,6,9,13$ \\
\hline$X$ ray 12 & $7,8,11,13$ & $1,2,3,4,5,6,9,10$ \\
\hline$X$ ray 13 & 8,12 & $1,2,3,4,5,6,7,9,10,11$ \\
\hline
\end{tabular}

Table 5: Statistical difference of each radiograph when compared to the others.

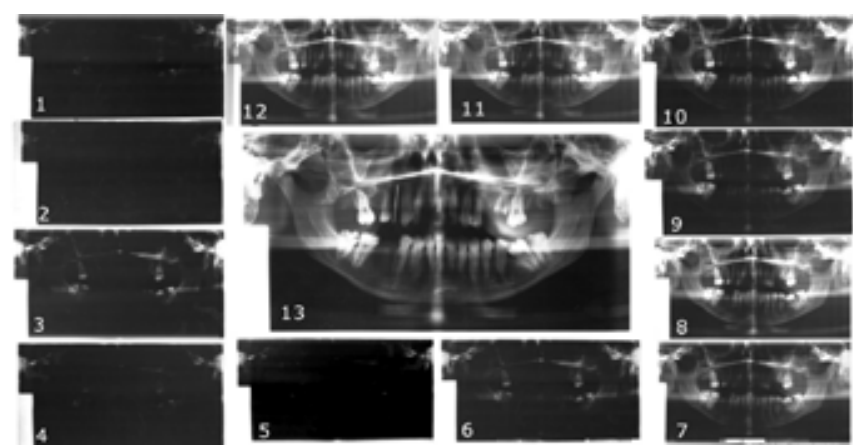

Figure 4: The test radiographs 1-13 with the best result image (13) at the center.

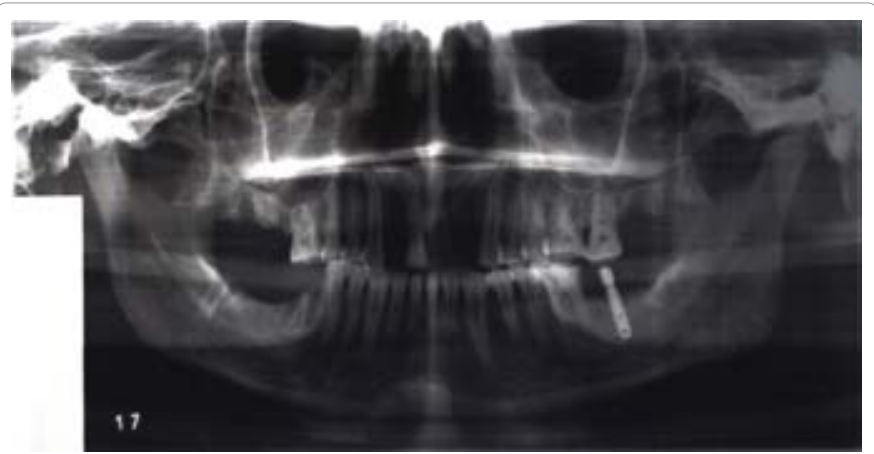

Figure 5: OPG of different geometry cranium.

After the choice for the two films technique, other orthopantomographies were made with different skulls since literature provides information that the geometry of the cranium can alter the quality results [20]. A shorter in length and also a longer length cranium were tested and the images were of similar quality as seen on Figure 5.

The 2.5 average achieved by the image 13 also can be interpreted that the digital radiography is indeed a superior quality exam that should be preferred whenever available or accepted in court issues, however the analogue images can be considered of satisfactory quality for forensic analysis.

\section{Conclusions}

Digital OPGs are one of the best quality exam when dry skull radiograph are necessary for scientific or forensic study (Figure 1). However when dealing with analog equipment, developing a panoramic film, intentionally exposed to light, and placing it inside the cassette between the new film and the intensifying screen, is the best way to achieve adequate radiographs. A maximum exposure of $63 \mathrm{Kv}$ and $06 \mathrm{~mA}$ preset should be selected and the use of an automatic process machine is preferred for better results. These steps should compensate the impairing lack of soft tissues faced by examiners when performing radiographic examination of skeletonized remains (Figure 4-5).

\section{Acknowledgments}

We thank CAPES for providing scholarships and stimulating the pursuit for knowledge. Also the Guarulhos IML, the University of São Paulo and the radiology department. A Special thanks for all the colleagues, who donated their time for the quality examination of the radiographs and the statistic analysis.

\section{References}

1. Andersen L, Juhl M, Solheim T, Borrman H (1995) Odontological identification of fire victims: potentialities and limitations. Int J Leg Med 107: 229-234.

2. Du Chesne A, Benthaus S, Teige K, Brinkmann B (2000) Post-mortem Orthopantomography - an aid in screening for identification purposes. Int Legal Med 113: 63-69.

3. Kahana T, Hiss J (1999) Forensic Radiology. Br J Radiol 72: 129-133.

4. Kvaal S (2006) Collection of post mortem data: DVI protocols and quality assurance. Forensic Sci Int 159: 12-14.

5. McKenna C (1999) Radiography in forensic dental identification- a review. J Forensic Odontostomatol 17: 47-53.

6. Mincer $\mathrm{HH}$ Chaudhry J, Blankenship J A, Turner E W ( 2008 ) Postmortem dental radiography. J Forensic Sci 53: 405-407.

7. Pretty I, Sweet D (2001) A look at forensic dentistry - Part 1: The role of teeth in the determination of human identity. Br Dent J 190: 359- 366

8. Rieperta T, Ulmckea D, Schwedenb F, Nafec B (2001) Identification of unknown dead bodies by $\mathrm{X}$-ray image comparison of the skull using the $\mathrm{X}$-ray simulation program FoXSIS. Forensic Sci Int 117: 89-98. 
Citation: Beaini TL, Miamoto Dias PE, Melani RFH (2011) Exposure Standards for Digital and Analogue Dry Skull Orthopantomography. J Forensic Res 2:115. doi:10.4172/2157-7145.1000115

Page 5 of 5

9. Sholl SA, Moody GH (2001) Evaluation of dental radiographic identification: an experimental study. Forensic Sci Int 115: $165-169$.

10. Valenzuela A, Martin de las Heras S, Marques T, Exposito N, Bohoyo JM (2000) The application of dental methods of identification to human burn victims in a mass disaster. Int J Legal Med 113:236-239.

11. Arbenz G (1988) Medicina legal e antropologia forense. $1^{\text {a }}$ edn. Atheneu, Rio de Janeiro.

12. Campobasso CP, Dell'Erba AS, Belviso M, Di Vella G (2007) Craniofacial identification by comparison of antemortem and postmortem radiographs - two case reports dealing with burnt bodies. Am J Forensic Med Pathol 28: 182-186.

13. Ferreira da Silva R, Pereira S, Mendes S, Marinho D, Daruge Junior E (2006) Radiografias odontológicas: Fonte de informação para a identificação humana. Odontologia Clínica-Científica 5: 239-242.

14. Wood RE (2006) Forensic aspects of maxillofacial radiology. Forensic Sci Int 159: 47-55.

15. Proffit R, Fields H (2007) Ortodontia Conteporânia. 4ª edn. Mosby-Elsevier, Rio de Janeiro.

16. White S, Pharoah M (2004) Oral radiology: Principals and interpretation. $5^{a}$ edn. Mosby, St. Louis.

17. Mason R (1988) A guide to dental radiology. $3^{\mathrm{a}}$ edn. Wright, London.

18. Rushton VE, Horner K (1996) The use of panoramic radiology in dental practice. J Dent 24: 185-201.

19. Mincer HH, Chaudhry J, Blankenship JA, Turner EW (2008) Postmortem Dental Radiography. Forensic Sci Int 53 : 405-407.
20. Gelbrich B, Gelbrich G, Lessig R (2009) Does the quality of dental images depend upon patient's age and sex? -Explanations from the forensic sciences. J Forensic Odontostomatol 27: 2-11.

21. Pereira I, Barros Filho A, Alvares B, Palomari E, Nanni L (2008) Determinação radiológica do índice e do tamanho craniano por mensuração dos diâmetros cranianos em uma população infantil brasileira. Radiol Bras 41 : 229-234.

22. Robinson MS, Bidmos MA (2009) The skull and humerus in the determination of sex: Reliability of discriminant function equations. Forensic Sci Int 186:86. e81- 86.e85.

23. Langland O, Langlais R, McDavid W, DelBaso A (1989) Panoramic Radiology $2^{\mathrm{a}}$ edn. Lea \& Febiger, Philadelphia.

24. Raghav N, Reddy SS, Giridhar AG, Murthy S, Yashodha Devi BK, et al. (2010) Comparison of the efficacy of conventional radiography, digital radiography, and ultrasound in diagnosing periapical lesions. Oral Surg Oral Med Ora Pathol Oral Radiol Endod 110: 379-385.

25. Yalcinkaya S, Kunzel A, Willers R, Thoms M, Becker J (2006) Subjective image quality of digitally filtered radiographs acquired by the Durr Vistascan system compared with conventional radiographs. Oral Surg Oral Med Oral Pathol Oral Radiol Endod 101: 643-651.

26. Kremer C, Racette S, Marton D, Sauvageau A(2008) Radiographs interpretation by forensic pathologists: a word of warning. Am J Forensic Med Pathol 29: 295296

27. Goga R, Chandler NP, Love RM (2004) Clarity and diagnostic quality of digitized conventional intraoral radiographs. Dentomaxillofac Radiol 33: 103-107. 